\title{
TEKNIK PEMBIBITAN EBONI DARI ANAKAN HASIL PERMUDAAN ALAM
}

\author{
Eboni Seedling Production Technique from Its Natural Regeneration
}

\author{
Hendromono \\ Pusat Litbang Hutan Tanaman \\ Kampus Badan Litbang Kehutanan, Jl. Gunung Batu No. 5, Bogor, Telp. (0251) 631238, Fax. (0251) 7520005 \\ Naskah masuk: 28 Februari 2007 ; Naskah diterima: 25 Juli 2007
}

\begin{abstract}
Ebony seed collection in a large number is difficult as ebony trees in natural habitat had been scarce, not all ebony trees produce fruit and its fruiting season is also different among locations. The purpose of this study was investigate technique for ebony seedling production from natural regeneration, which can produce seedlings with high survival rate and quality. The experimental design used is Randomized Complete Block Design within $2 \times 3$ Factorial Experiment. Treatments are wild seedling size $\left(A_{0}=\right.$ small wild seedling; $A_{1}=$ large wild seedling) and duration in concave cover ( $B_{0}=1.5$ months, $B_{2}=2$ months, $B_{3}=2.5$ months). Each combination treatment consist of 25 wild seedling and replicated four times. The results showed that the large wild seedling (12.6 cm height, $1.8 \mathrm{~mm}$ stem diameter) was better than those of small wild seedling $(8.4 \mathrm{~cm}$ height, $1.3 \mathrm{~mm}$ stem diameter). Before tending in shaded area, the wild seedlings must be kept in plastic concave cover under shade for two months. Hardening off seedlings should be carried out by reducing shade intensity and frequency of watering.
\end{abstract}

Key words : ebony, plastic concave cover, seedling, wild seedling

\begin{abstract}
ABSTRAK
Pengumpulan benih eboni dalam jumlah banyak tidak mudah karena tegakan eboni di tempat tumbuh alaminya sudah jarang dan tidak semua pohon eboni berbuah serta musim berbuahnya berbeda antara tempat satu dengan lainnya. Tujuan penelitian ini adalah untuk mengetahui cara pembibitan eboni dari anakan permudaan alam yang dapat menghasilkan bibit yang berdaya hidup dan bermutu tinggi. Rancangan percobaan yang digunakan adalah Rancangan Acak Lengkap Berkelompok dalam Percobaan Faktorial 2 x 3. Perlakuan berupa ukuran bibit ( $\mathrm{A}_{0}=$ anakan kecil; $\mathrm{A}_{1}=$ anakan besar) dan lama dalam sungkup ( $\mathrm{B}_{0}=1,5$ bulan, $\mathrm{B}_{1}=2$ bulan, $\mathrm{B}_{2}=2,5$ bulan). Tiap kombinasi perlakuan terdiri dari 25 anakan dan diulang empat kali. Hasil penelitian menunjukkan bahwa anakan yang berukuran besar (tinggi 12,6 cm, diameter 1,8 mm) lebih baik untuk bahan pembibitan daripada anakan berukuran kecil (tinggi $8,4 \mathrm{~cm}$, diameter 1,3 mm). Sebelum dipelihara dibawah naungan, anakan dimasukkan dalam sungkup plastik di bawah naungan selama dua bulan. Pengerasan bibit sebelum ditanam di lapang sebaiknya dilakukan dengan mengurangi intensitas naungan dan frekuensi penyiraman.
\end{abstract}

Kata Kunci : anakan permudaan alam, bibit, eboni, sungkup plastik.

\section{PENDAHULUAN}

Salah satu jenis pohon andalan setempat di Sulawesi Selatan, Sulawesi Tengah dan Sulawesi Utara yang mulai langka adalah eboni (Diospyros celebica Bakh.) (Suriarahardja dan Wasono, 1996). Pohon ini merupakan salah satu jenis Diospyros di dunia yang tumbuh secara alami hanya di Sulawesi dan kayunya sangat diminati, baik di dalam maupun di luar negeri. Kayu eboni banyak digunakan untuk meubel, bahan bangunan, hiasan, ukiran dan perabot rumah tangga dan alat musik (Soerianegara, et al. 1995). Penggunaan perabot rumah tangga dari kayu eboni dapat meningkatkan status sosial orang Jepang (Kuhon et al., 1987). Kayu eboni termasuk salah satu jenis kayu hitam yang 
sangat mahal harganya. Pada tahun 1967 harga kayu eboni setiap ton sekitar US \$ 20 (Surianegara, 1967), dua puluh tahun kemudian harga satu meter kubik (sekitar 1,2 ton) kayu ini meningkat menjadi US \$ 2000 (Kuhon, et al. 1987) dan pada tahun 1989 dilaporkan harga kayu gergajiannya di luar negeri mencapai US \$ 5000 tiap meter kubik (Anonim, 1989). Berdasarkan surat edaran Menteri Perindustrian dan Perdagangan No. 160/Dj PLN/VI/2001 tentang penetapan harga patokan barangbarang ekspor, harga kayu gergajian, kayu belahan dan tiang pancang kelompok eboni sebesar US $\$ 6.000 / \mathrm{m}^{3}$. Dengan meroketnya harga kayu tersebut banyak orang menebangnya di hutan alam sehingga apabila tidak dikonservasi dan dibudidayakan dikhawatirkan akan punah.

Musim berbuah jenis pohon eboni tergolong berbeda antara habitat satu dengan lainnya serta tidak semua pohon berbuah setiap tahun. Pohon penghasil kayu mewah ini hidupnya mengelompok. Apabila ada pohon eboni yang hidup sendiri, tidak akan menghasilkan buah. Pohon eboni di habitat alaminya sudah mulai sulit ditemukan. Maka untuk memperoleh benih eboni tidaklah mudah, harus menunggu waktu yang tepat saat pohon menghasilkan buah yang masak. Selain itu buah eboni sering dimakan kelelawar, monyet atau binatang lain sehingga bijinya tersebar di sekitar pohon induknya. Pengumpulan benih yang terlambat akan sia-sia karena daya berkecambah benih cepat menurun dan sering benih yang jatuh diserang jamur Peniulliopsis clavariaeformis (Santoso, 1997). Dalam kenyataannya lebih mudah menemukan anakan alam eboni di sekitar kelompok pohon eboni daripada benih eboni yang viabel. Keterlambatan pemungutan buah yang umumnya berkaitan dengan terlambat turunnya dana reboisasi untuk kegiatan pembibitan, memaksa pengada bibit eboni mencabut anakan yang tumbuh di bawah pohon induk. Penggunaan anakan alam eboni untuk pembibitan memerlukan perlakuan khusus agar tingkat keberhasilannya tinggi. Santoso (1997) menyarankan anakan alam yang telah ditanam di polybag dimasukkan ke dalam sungkup plastik selama 1 sampai 2 bulan. Untuk memastikan lamanya dipelihara di dalam sungkup, perlu penelitian lama pemeliharaan dan ukuran anakan yang tepat pada saat dicabut.

Tujuan penelitian ini adalah untuk mendapatkan teknik pemeliharaan bibit cabutan eboni agar mempunyai mutu fisik dan tingkat keberhasilan tinggi.

\section{BAHAN DAN METODE}

\section{A. Lokasi}

Penelitian dilakukan di persemaian Pusat Penelitian dan Pengembangan Hutan dan Konservasi Alam (P3HKA), Bogor. Anakan eboni berasal dari Hutan Penelitian Cikampek (Karawang) dan Carita (Pandeglang).

\section{B. Bahan dan Alat}

Bahan penelitian berupa anakan eboni sebanyak 750 batang. Medium semai berupa tanah Oxisol dari persemaian P3HKA, Bogor. Kantong plastik hitam ukuran lebar $12 \mathrm{~cm}$, panjang $20 \mathrm{~cm}$. Pupuk NPK ( $7: 5: 15)$ lengkap, seberat 375 gram.

\section{Metode}

Anakan alam eboni dicabut hati-hati dengan cara puteran pada tanggal 1 Agustus 2003 dari Hutan Penelitian Cikampek dan Carita. Bahan penelitian tersebut dibungkus dengan pelepah batang pisang dan dibawa ke persemaian P3HKA, Bogor. Anakan selanjutnya ditanam dalam wadah plastik yang telah berisi top-soil Oxisol.Sifat fisik dan kimia tanah tercantum pada Tabel 1. Anakan dalam wadah kemudian ditempatkan di dalam sungkup plastik transparan yang tertutup rapat di bawah 
naungan paranet dengan intensitas cahaya sekitar $25 \%$. Setiap pagi hari anakan disiram air kran. Anakan dibedakan yang berukuran kecil dan besar. Setelah mencapai umur 1,5, 2 dan 2,5 bulan bibit dikeluarkan dari sungkup dan tetap dipelihara di bawah naungan tersebut. Bibit diberi pupuk NPK (7 : $5: 15$ ) lengkap seberat 0,5 gram per bibit dan dipelihara di persemaian sampai siap ditanam selama 9 bulan.

Tabel (Table)1. Sifat fisik dan kimia tanah lapisan atas Oxisol di persemaian Pusat Litbang Hutan dan Konservasi Alam, Bogor (Physical and chemical characteristics of Oxisol top-soil at nursery of Forest and Nature Conservation Research and Development Centre, Bogor)

\begin{tabular}{|c|c|c|}
\hline $\begin{array}{c}\text { Sifat tanah } \\
\text { (Soil } \text { characteristics) }\end{array}$ & $\begin{array}{l}\text { Nilai } \\
\text { (Value) }\end{array}$ & $\begin{array}{l}\text { Kelas } \\
\text { (Class) }\end{array}$ \\
\hline \multicolumn{3}{|l|}{ Tekstur (Texture) } \\
\hline Pasir (Sand) & 10,00 & \\
\hline Debu (Silt) & 17,50 & liat (clay) \\
\hline Liat (Clay) & 72,50 & \\
\hline $\mathrm{pH} \mathrm{H} \mathrm{H}_{2} \mathrm{O}$ & 5,80 & sedang (medium) \\
\hline $\mathrm{pH} \mathrm{KCl}$ & 4,85 & sedang (medium) \\
\hline $\mathrm{C}(\%)$ & 2,15 & sedang (medium) \\
\hline $\mathrm{N}(\%)$ & 0,19 & rendah (low) \\
\hline $\mathrm{C} / \mathrm{N}$ & 11,32 & sedang (medium) \\
\hline $\mathrm{P}_{2} \mathrm{O}_{5}$ ekstrak $\mathrm{HCl}(\mathrm{mg} / 100 \mathrm{~g})$ & 17,00 & rendah (low) \\
\hline K2O ekstrak HCl (mg/100 g) & 96,50 & sangat tinggi (very high) \\
\hline \multicolumn{3}{|l|}{ Nilai tukar kation (Cation exchange capacity) (me/100 g) } \\
\hline $\mathrm{K}(\mathrm{me} / 100 \mathrm{~g})$ & 0,45 & sedang (medium) \\
\hline $\mathrm{Na}(\mathrm{me} / 100 \mathrm{~g})$ & 0,15 & rendah (low) \\
\hline $\mathrm{Ca}(\mathrm{me} / 100 \mathrm{~g})$ & 5,40 & sedang (medium) \\
\hline $\mathrm{Mg}(\mathrm{me} / 100 \mathrm{~g})$ & 5,30 & rendah (low) \\
\hline Kapasitas adsorbsi (Adsorbtion capacity) (me/100 g) & 21,85 & sedang (medium) \\
\hline Kejenuhan basa (Base saturation) (\%) & 32,50 & rendah (low) \\
\hline
\end{tabular}

Catatan (Note): Dianalisis di Pusat Penelitian Tanah dan Agroklimat, Bogor (Analysed at the Centre for Agroclimate and Soil Research, Bogor)

Rancangan percobaan yang digunakan berupa Rancangan Acak Lengkap Berkelompok dalam Percobaan Faktorial 2 x 3. Perlakuan berupa ukuran anakan (A), dan lama dalam sungkup (B).

Ao = anakan eboni ukuran kecil (tinggi 8,3 \pm 0,6, diameter batang 1,29 $\pm 0,10$ )

$\mathrm{A}_{1}=$ anakan eboni ukuran besar (tinggi 12,6 $\pm 2,9$, diameter batang 1,78 $\pm 0,34$ )

$\mathrm{B}_{1}=$ lama pemeliharaan dalam sungkup 1,5 bulan dengan intensitas cahaya $25 \%$.

$\mathrm{B}_{2}=$ lama pemeliharaan dalam sungkup 2,0 bulan dengan intensitas cahaya $25 \%$

$\mathrm{B}_{3}=$ lama pemeliharaan dalam sungkup 2,5 bulan dengan intensitas cahaya $25 \%$

Tiap kombinasi perlakuan terdiri dari 25 anakan dan diulang 5 kali, sehingga jumlah anakan yang diteliti sebanyak 750 batang. Parameter yang diukur adalah pertambahan tinggi, diameter dan angka indeks mutu bibit. Angka indeks mutu bibit dihitung menggunakan rumus Dickson et al. (1960): 
Indeks mutu $=$

Berat kering bibit total (g)

$$
\frac{\text { Tinggi total }(\mathrm{cm})}{\text { Diameter batang }(\mathrm{mm})}+\frac{\text { Berat kering bibit bagian atas }(\mathrm{g})}{\text { Berat kering bibit bagian akar }(\mathrm{g})}
$$

\section{Analisis Data}

Data hasil pengukuran selama 4 dan 9 bulan di persemaian dianalisis dengan sidik ragam. Apabila ada perlakuan atau kombinasi perlakuan yang berpengaruh nyata, diuji lebih lanjut dengan metode Duncan (Gomez \& Gomez, 1984).

\section{HASIL DAN PEMBAHASAN}

Pemungutan buah eboni yang terlambat (pertengahan tahun) yang berkaitan dengan terlambat turunnya dana untuk kegiatan reboisasi dan penghijauan, mengakibatkan orang harus mencabut anakan eboni dari permudaan alam. Anakan eboni yang umurnya belum satu tahun umumnya banyak ditemukan di sekitar pohon induknya. Jumlah anakan eboni yang tumbuh terus menjadi sapihan (sapling), menurun drastis pada tahun ke dua setelah musim berbuah. Oleh karena itu anakan yang berumur di bawah satu tahun perlu dimanfaatkan daripada mati dengan sendirinya.

Hasil penelitian ini menunjukkan bahwa bibit eboni yang dipelihara di persemaian selama 4 bulan dan 9 bulan terlihat interaksi nyata antara ukuran bibit dengan lama penyungkupan pada pertambahan diameter batang bibit, persen jadi bibit dan angka indeks mutu bibit, tetapi tidak nyata pada pertambahan tinggi bibit (Tabel 2). Ukuran anakan alam berpengaruh nyata terhadap pertambahan tinggi bibit selama 9 bulan, tetapi tidak berpengaruh nyata selama bibit berumur 4 bulan (Tabel 3).

Pertambahan diameter batang bibit dari anakan yang berukuran besar dalam sungkup plastik selama 1,5 bulan $\left(\mathrm{A}_{1} \mathrm{~B}_{1}\right)$ sama dengan bibit dari anakan berukuran sama dalam sungkup 2 bulan $\left(A_{1} B_{2}\right)$, namun jauh lebih cepat daripada bibit dari anakan berukuran kecil $\left(A_{0}\right)$ atau besar $\left(A_{1}\right)$ dalam sungkup 2,5 bulan $\left(B_{3}\right)$. Persen jadi bibit dari anakan berukuran besar $\left(A_{1}\right)$ dalam sungkup 1,5 bulan $\left(B_{1}\right)$ jauh lebih rendah daripada bibit dari anakan berukuran besar dalam sungkup 2 bulan $\left(B_{2}\right)$ maupun 2,5 bulan $\left(\mathrm{B}_{3}\right)$. Bibit dari anakan berukuran kecil dalam sungkup 2 atau 2,5 bulan, cenderung persen jadinya lebih rendah daripada bibit dari anakan berukuran besar dalam sungkup yang sama jangka waktunya, karena secara fisiologi bibit berukuran besar lebih sehat, namun secara statistik tidak berbeda nyata.

Mutu fisik bibit yang diwakili oleh angka indeks mutu yang terbaik adalah pada bibit dari anakan berukuran besar $\left(A_{1}\right)$ yang dipelihara dalam sungkup selama 2 bulan $\left(B_{2}\right)$. Kombinasi perlakuan lain mutu fisiknya lebih rendah dan berbeda nyata dengan bibit dari anakan berukuran besar dan dipeliharan dalam sungkup selama 2 bulan $\left(\mathrm{A}_{1} \mathrm{~B}_{2}\right)$ (Tabel 2). 
Tabel (Table) 2. $\quad$ Pertambahan diameter batang dan persen jadi bibit eboni selama 4 dan 9 bulan serta angka indeks mutu bibit di persemaian (Stem diameter increment and survival percentage of eboni seedling for 4 and 9 months and quality index value of seedling in the nursery)

\begin{tabular}{|c|c|c|c|c|c|}
\hline \multirow[t]{2}{*}{$\begin{array}{l}\text { Perlakuan } \\
\text { (Treatment) }\end{array}$} & \multicolumn{2}{|c|}{$\begin{array}{l}\text { Diameter batang } \\
\text { (Stem diameter }) \\
(\mathrm{mm})\end{array}$} & \multicolumn{2}{|c|}{$\begin{array}{c}\text { Persen jadi } \\
\text { (Survival percentage) } \\
\text { (\%) }\end{array}$} & \multirow{2}{*}{$\begin{array}{l}\text { Indeks mutu } \\
\text { (Quality index) } \\
9 \text { bulan } \\
\text { (9 month) }\end{array}$} \\
\hline & $\begin{array}{c}4 \text { bulan } \\
\text { (4 month) }\end{array}$ & $\begin{array}{c}9 \text { bulan } \\
\text { (9 month) }\end{array}$ & $\begin{array}{c}4 \text { bulan } \\
\text { (4 month) }\end{array}$ & $\begin{array}{c}9 \text { bulan } \\
\text { (9 month) }\end{array}$ & \\
\hline $\begin{array}{l}\mathrm{A}_{0} \mathrm{~B}_{1}=\text { anakan kecil, sungkup } 1,5 \\
\text { bulan (smal shoots, } 1.5 \text { months in } \\
\text { cover) }\end{array}$ & $0,53 \mathrm{ab}$ & 1,04 bc & 84,0 bc & $83,0 \mathrm{ab}$ & $0,191 \mathrm{~b}$ \\
\hline $\begin{array}{l}\mathrm{A}_{0} \mathrm{~B}_{2}=\text { anakan kecil, sungkup } 2,0 \\
\text { bulan (small shoots, } 2.0 \text { months in } \\
\text { cover) }\end{array}$ & 0,36 bc & 0,92 с & $93,0 \mathrm{ab}$ & $90,0 \mathrm{a}$ & $0,255 \mathrm{~b}$ \\
\hline $\begin{array}{l}\mathrm{A}_{0} \mathrm{~B}_{3}=\text { anakan kecil, sungkup } 2,5 \\
\text { bulan (smal shoots, } 2.5 \text { months in } \\
\text { cover) }\end{array}$ & 0,36 bc & 1,02 bc & $88,0 \mathrm{ab}$ & $82,0 \mathrm{ab}$ & $0,227 \mathrm{~b}$ \\
\hline $\begin{array}{l}\mathrm{A}_{1} \mathrm{~B}_{1}=\text { anakan besar, sungkup } 1,5 \\
\text { bulan (large shoots, } 1.5 \text { months in } \\
\text { cover) }\end{array}$ & $0,62 \mathrm{a}$ & $1,54 \mathrm{a}$ & $75,0 \quad c$ & 69,0 b & $0,146 \mathrm{~b}$ \\
\hline $\begin{array}{l}\mathrm{A}_{1} \mathrm{~B}_{2}=\text { Anakan besar, sungkup } 2,0 \\
\text { bulan (large shoots, } 2.0 \text { months in } \\
\text { cover) }\end{array}$ & $0,61 \mathrm{a}$ & $1,56 \mathrm{a}$ & $95,0 \mathrm{ab}$ & $92,0 \mathrm{a}$ & $0,575 \mathrm{a}$ \\
\hline $\begin{array}{l}\mathrm{A}_{1} \mathrm{~B}_{3}=\text { anakan besar, sungkup } 2,5 \\
\text { bulan (large shoots, } 2.5 \text { months in } \\
\text { cover) }\end{array}$ & $0,24 \quad \mathrm{c}$ & $1,24 \mathrm{~b}$ & $98,0 \mathrm{a}$ & $93,0 \mathrm{a}$ & $0,296 \mathrm{~b}$ \\
\hline
\end{tabular}

Catatan (Note): $\quad$ Nilai dalam kolom yang diikuti oleh huruf yang sama, tidak berbeda nyata pada taraf $95 \%$ menurut uji Duncan (Values in columns followed by the same letters, are not significantly different at $95 \%$ level, according to Duncan test).

Pertambahan tinggi bibit selama 4 bulan belum berbeda nyata karena selama jangka waktu tersebut merupakan fase penyesuaian bibit dengan kondisi lingkungan yang baru sehingga perbedaan pertumbuhan belum banyak, tetapi setelah bibit berumur 9 bulan di persemaian terlihat perbedaan yang nyata, karena bibit yang berasal dari anakan berukuran besar pertambahan tingginya lebih cepat daripada bibit yang berasal dari anakan berukuran kecil (Tabel 3).

Tabel (Table) 3. Pertambahan tinggi bibit eboni selama 4 dan 9 bulan di persemaian (High increment of eboni seedlings for 4 and 9 month in the nursery).

\begin{tabular}{|l|c|c|}
\hline \multicolumn{2}{|c|}{ Perlakuan (Treatment) } & \multicolumn{2}{|c|}{$\begin{array}{c}\text { Pertambahan tinggi (Height increment) } \\
\text { (cm) }\end{array}$} \\
\cline { 2 - 3 } & 4 bulan (4 month) & 9 bulan $(9$ month) \\
\hline Ao = Anakan kecil (small shoots) & $1,75 \mathrm{a}$ & $5,53 \mathrm{a}$ \\
\hline $\mathrm{A}_{1}=$ Anakan besar (large shoots) & $1,91 \mathrm{a}$ & $8,04 \mathrm{~b}$ \\
\hline
\end{tabular}

Catatan (Note): $\quad$ Nilai dalam kolom yang diikuti oleh huruf yang sama, tidak berbeda nyata pada tingkat kepercayaan 95 $\%$ menurut uji Duncan (Values in columns followed by the same letters, are not significantly different at $95 \%$ confident level, according to Duncan test). 
Hasil penelitian ini menunjukkan bahwa anakan cabutan eboni yang berukuran besar (tinggi $12,6 \mathrm{~cm}$, diameter $1,8 \mathrm{~mm}$ ), setelah 9 bulan dipelihara di persemaian rata-rata pertambahan diameter dan tingginya lebih cepat 1,45 kali daripada anakan yang berukuran kecil (tinggi 8,4 cm, diameter 1,3 mm). Hal ini kemungkinan karena pada musim buah masak, benih yang jatuh lebih awal mempunyai waktu untuk tumbuh lebih lama daripada benih yang jatuh belakangan, sehingga pada waktu dicabut ukurannya lebih besar. Kondisi ini akan terbawa terus sampai tanaman dewasa. Anakan yang lebih besar cenderung lebih siap untuk beradaptasi dan tumbuh lebih cepat dibandingkan dengan anakan yang lebih kecil, karena anakan yang lebih besar (batang dan daun) umumnya lebih sehat sehingga kemampuan untuk menghadapi perubahan lingkungan lebih tinggi daripada anakan berukuran lebih kecil. Hasil yang serupa juga terjadi pada bibit korbaril (Hymenaea courbaril) yang tingginya $35 \mathrm{~cm}$, diameter batang 3,7 $\mathrm{mm}$ (bibit besar), setelah dua tahun lima bulan di lapang pertumbuhan tinggi dan diameter batang tanaman, masing-masing 1,2 dan 1,3 kali bibit berukuran kecil (tinggi $19 \mathrm{~cm}$, diameter batang 2,9 mm) (Hendromono, 1998a). Demikian juga pada bibit pterigota (Pterygota alata); bibit berukuran tinggi 22,0 $\mathrm{cm}$ dan diameter batang 3,4 mm dibandingkan dengan bibit berukuran tinggi 18,4 $\mathrm{cm}$ dan diameter batang 3,1 $\mathrm{mm}$, setelah 9 bulan di lapang pertumbuhan tinggi dan diameter batang tanaman dari bibit besar masing-masing 2,4 dan 1,8 kali tanaman dari bibit yang lebih kecil (Hendromono, 1998b).

Menurut South (1993) pada tahun 1979 Bacon melaporkan bahwa jenis Pinus elliottii di Australia produksi kayunya makin meningkat apabila diameter batang bibitnya makin besar. Bibit yang berukuran diameter batang 6,8 mm volume kayunya pada umur 10 tahun $178 \mathrm{~m}^{3} \mathrm{ha}^{-1}$ dibandingkan dengan bibit berdiameter batang 3,8 mm volume kayunya hanya $78 \mathrm{~m}^{3} \mathrm{ha}^{-1}$. Hasil serupa juga dilaporkan oleh Clark dan Phares tahun 1961, bahwa bibit P. Echinata di selatan Missouri yang diameter batangnya 5,1 mm setelah menjadi tanaman umur 21 tahun volume kayunya $26 \%$ lebih besar daripada tanaman yang berasal dari bibit berdiameter batang 3,8 $\mathrm{mm}$. Contoh lain bibit P. elliottii yang tingginya 29,5 cm dan 14,5 cm ditanam di Hutan Penelitian Santee, Carolina Selatan. Setelah tanaman berumur 19 tahun, volume kayu pada tanaman yang berasal dari bibit yang tinggi, 80 \% lebih besar daripada tanaman yang berasal dari bibit lebih pendek. Bibit $P$. taeda yang tingginya $30,5 \mathrm{~cm}$ dibandingkan dengan bibit dengan tinggi $13,5 \mathrm{~cm}$, perbedaan volumenya setelah 10 tahun di lapang sebesar 92 \% lebih besar pada bibit yang lebih tinggi. Perbedaan ini bukan karena persen jadinya, tetapi karena perbedaan kecepatan pertumbuhan (Hatchell et al., 1972).

Angka indeks mutu dapat merupakan petunjuk mutu fisik bibit. Makin besar angka indeks mutu menandakan bahwa bibit makin baik mutunya. Hal ini telah terbukti pada tanaman $P$. alata (Hendromono, 1998b). Apabila mempertimbangkan angka indeks mutu, pertambahan diameter, tinggi dan persen jadi bibit pada umur 9 bulan, maka mencabut anakan eboni yang berukuran lebih besar (tinggi 12,6 cm, diameter 1,8 mm) kemudian dipelihara dalam sungkup plastik di bawah naungan yang intensitas cahayanya sekitar 25 \% selama 2 bulan, selanjutnya dipelihara di persemaian di bawah naungan tersebut, merupakan cara terbaik agar anakan eboni tetap hidup dan mutu fisiknya tinggi. Pemeliharaan dalam sungkup yang lebih lama (2,5 bulan) pada bibit dari anakan berukuran besar, menghasilkan bibit yang mutu fisiknya lebih rendah daripada yang disungkup selama 2 bulan (Tabel 2). Selain itu tenaga yang diperlukan untuk memelihara bibit dalam sungkup lebih banyak. Pada bibit dari anakan besar yang disungkup selama 1,5 bulan, mutu fisiknya juga lebih rendah daripada bibit yang disungkup 2 bulan (Tabel 2). Menurut Sallata dan Renden (1991) anakan alam eboni yang dicabut untuk dipelihara di persemaian dapat yang berdaun 2 sampai 8 helai. 


\section{KESIMPULAN DAN SARAN}

1. Anakan eboni hasil permudaan alam untuk pengadaan bibit, apabila pencabutannya dilakukan pertengahan tahun sebaiknya dipilih yang berukuran besar (tinggi 12,6 cm, diameter batang $1,8 \mathrm{~mm}$ ) dan sehat daripada yang berukuran kecil (tinggi 8,4 cm, diameter batang 1,3 mm) agar pertumbuhan dan persen jadinya tinggi.

2. Pembibitan eboni dengan memanfaatkan anakan alam, perlu dilakukan pemeliharaan dalam sungkup plastik selama 2 bulan di bawah naungan yang intensitas cahayanya sekitar $25 \%$, selanjutnya sungkup dibuka dan bibit dipelihara di bawah naungan tersebut sampai siap tanam.

3. Pencabutan anakan eboni perlu dilakukan secara hati-hati dengan cara puteran (mencongkel tanah disekeliling anakan) agar perakaran anakan tidak banyak yang terputus. Anakan eboni yang dicabut sebaiknya telah berdaun lebih dari 2 helai.

4. Sebelum bibit eboni ditanam di lapang, perlu pengerasan bibit selama sekitar 2 minggu dengan cara mengurangi intensitas naungan dan penyiraman bibit.

\section{DAFTAR PUSTAKA}

Anonim.1989. Persoalan kayu hutan dikeluhkan kepada wapres. Kompas, 22 Sept. 1989. Hal 9.

Bacon, G.J. 1979. Seedling Morphology as an Indicator of Planting Stock Quality In Conifers. Presented at Workshop on 'Techniques for evaluating planting stock quality'. August 1979. New Zealand. (unpublished).

Clark, F.B. and R.E. Phares. 1961. Graded Stock Means Greater Yields for Shortleaf Pine. USDA Forest Service. Central State Forest Exp.Sta.Techn. Pap.181. 5p.

Dickson,A., A.L. Leaf and J.F. Hosner. 1960. Quality Appraisal of White Spruce and White Pine Seedling Stocks in Nurseries. Forest Chronicle. 36 (1): 10 - 13.

Gomez, K.A. and Gomez, A.,A. 1984. Statistical Procedures for Agricultural Research $2^{\text {nd }}$ Ed. John Wiley \& Sons. New York.

Hatchell, G.E., K.W. Dorman, and D.G. Langdon. 1972. Performance of Loblolly and Slash Pines Nursery Selections. Forest Science, 18: 308-214.

Hendromono. 1998a. Teknik Penanaman Korbaril (Hymenaea courbaril) pada Areal Alang-alang. Bul. Pen. Hut. No. 617: 19-28.

Hendromono. 1998b. Pengaruh Media Organik dan Tanah Mineral terhadap Mutu Bibit Pterygota alata Roxb. Bul. Pen. Hut. No. 17: 55-64.

Kuhon, A., L. Pattiradjawane dan R. Badil. 1987. Kayu hitam yang semakin hitam. Kompas 1 Nopember 1987. hal 2.

Sallata, K. dan R. Renden. 1991. Sistem Cabutan pada Anakan Alam Eboni (Diospyros celebica Bakh). Jurnal Penelitian Kehutanan. Balai Penelitian Kehutanan Ujung Pandang. 5(1): 30-34.

Santoso, B. 1997. Pedoman Teknis Budidaya Eboni (Diospyros celebica Bakh.). BPK Ujung Pandang. Ujung Pandang.

Soerianegara, I. 1967. Beberapa Keterangan tentang Jenis-jenis Pohon Eboni Indonesia. Pengumuman No. 92. Lembaga Penelitian Hutan, Bogor. 
Soerianegara, I., D.S. Alonzo., S. Sudo and M.S.M. Sosef. 1995. Diospyros L. In Plant Resources of South-East Asia No. 5(2). Timber trees: minor commercial timbers. Lemmens, R.H.M.J., I. Soerianegara. and W.C. Wong. (eds.). Backhuys Publishers. Leiden.

South, D.B. 1993. Rationale for Growing Southern Pine Seedlings at Low Seedbed Densities, review paper. New Forest, 7: 63-92.

Suriarahardja, S dan D. Wasono. 1996. Informasi Jenis Kayu Andalan Setempat (JAS) di Seluruh Indonesia. Info Hutan 1 (1): 1-26. 